\title{
Incidence of ocular melanoma in the general population and in glaucoma patients
}

\author{
C Huerta, L A García Rodríguez
}

Intraocular melanomas are the most common primary ocular malignancy in white people accounting for approximately $70 \%$ of all eye malignancies in adults. ${ }^{1}$ Most ocular melanomas arise from uveal melanocytes distributed throughout the stroma of the choroid, ${ }^{2}$ only $4 \%-10 \%$ of uveal melanomas originate in the iris. ${ }^{3}$

Data on the incidence of intraocular melanoma are limited with estimates of incidence rate (IR) reported between 4 and 8 per million per year. ${ }^{1}$ Known risk factors include advanced age and white people but there are very few studies describing other potential risk factors for uveal melanoma. ${ }^{4}$

We conducted a study using the General Practice Research Database (GPRD) to estimate the incidence rate of ocular melanoma in the general population. As a secondary objective, we investigated whether glaucoma is associated with ocular melanoma.

\section{Methods}

Our source population came from the GPRD, which contains clinical information on about 3 million patients recorded by general practitioners in the United Kingdom. The geographical distribution of the practices participating in the GPRD is representative of the UK population, apart from small variations between regions. ${ }^{5}$ Recent comparisons of age and sex distribution with the National Population Census have shown these to be closely similar. ${ }^{5}$ The general practitioners systematically record data on their patients and sent them anonymously to the Medicine Control Agency. A previous validation study has documented that over $90 \%$ of all referrals present in the manual records in the GPs' offices are entered into the GPs' computers with a code that reflects the clinical diagnosis. ${ }^{6}$ An additional requirement of this data resource is that the indication for any new course of treatment be entered in the computer. In addition, the GP may record laboratory results and other medical data in a free text comment field. A modification of the OXMIS classification is used to code specific diagnoses, and a drug dictionary based on the Prescription Pricing Authority drug dictionary is used to record drugs. We identified all patients 40 to

Centro Español de Investigación Farmacoepidemiológica (CEIFE), Almirante 28; $2^{\circ}, 28004$ Madrid, Spain

Correspondence to: Dr Huerta

(chuerta@ceife.es)

Accepted for publication 4 December 2000 patients, and of them 85 were confirmed as cases of glaucoma (confirmation rate of $89 \%$ ). Our study included 812853 people in the general population cohort and 24131 patients in the glaucoma cohort. We followed up both cohorts until the earliest occurrence of one of the following end points: ocular melanoma, cancer other than ocular melanoma, death or 30 September 1998 . We then identified in both cohorts those with a code of ocular melanoma during the study period and reviewed manually their complete computerised medical patient history. After this review 64 patients were retained as potential cases of ocular melanoma. To confirm the diagnosis of ocular melanoma, we sent a questionnaire to the general practitioners of all 64 patients requesting their confirmation as an incident case of ocular melanoma and a copy of all hospital summaries as well as letters from the specialist related to this diagnosis. We received valid information in 60 cases, of these 45 were confirmed as incident cases of ocular melanoma and 15 were excluded (the diagnosis was not confirmed in two cases, nine had other eye pathology and four had melanoma in other locations).

We calculated the incidence rate of ocular melanoma and $95 \%$ confidence intervals in the two cohorts, general population and glaucoma. Incidence rates were calculated dividing the number of cases of ocular melanoma by the corresponding number of person years at risk. We then compared the incidence rate in the cohort of glaucoma patients with the incidence rate in the general population and calculated the relative risk and exact $95 \%$ confidence intervals of ocular melanoma associated with glaucoma.

\section{Results}

The total follow up experience in the general population was 3869218 person years and 90612 in the glaucoma cohort. Forty five patients were confirmed as incident cases of ocular melanoma in the general population cohort and there was no confirmed case of ocular melanoma in the glaucoma cohort. From the questionnaires we could only obtain information on type of ocular melanoma in 29 cases. Among these, choroidal melanoma accounted for $86 \%$ of them. The site was available in 32 cases with 19 located in the right eye and 13 in the left. The incidence of ocular melanoma in the general population cohort increased considerably with age and was similar among men and women (table 1). The overall annual incidence rate in the general population cohort was 11.6 per 1000000 persons years $(95 \%$ CI 8.7, 15.6). The relative risk 
Table 1 Incidence of ocular melanoma by age and sex in the general population

\begin{tabular}{|c|c|c|c|}
\hline & Person years & $\begin{array}{l}\text { Ocular } \\
\text { melanoma } \\
\text { cases }\end{array}$ & $\begin{array}{l}\text { Incidence rate } \\
(95 \% C I)^{*}\end{array}$ \\
\hline \multicolumn{4}{|l|}{ Age } \\
\hline $40-64$ & 2547992 & 22 & $8.6(5.7,13.1)$ \\
\hline$\geqslant 65$ & 1321227 & 23 & $17.4(11.6,26.1)$ \\
\hline \multicolumn{4}{|l|}{ Sex } \\
\hline Male & 1771713 & 21 & $11.8(7.8,18.1)$ \\
\hline Female & 2097506 & 24 & $11.4(7.7,17.0)$ \\
\hline Total & 3869219 & 45 & $11.6(8.7,15.6)$ \\
\hline
\end{tabular}

^Incidence rate per 1000000 person years.

of ocular melanoma among glaucoma patients compared with the general population was 0 (95\% CI 0, 2.9).

\section{Discussion}

In our study we estimated the incidence rate of ocular melanoma to be about 11 per 1000000 person years. This incidence is in the range reported by other authors ${ }^{17}$ and actually slightly greater. This finding would exclude any major underascertainment of ocular melanoma in our study. Also, we found a major increased risk with old age as previously described. ${ }^{4}$ We did not find any case of ocular melanoma in the glaucoma population. Based on these results, it can be ruled out with confidence an incidence rate greater than 30 per 1000000 person years in the glaucoma population. In summary, we did not find a major increased risk of ocular melanoma associated with glaucoma.

We thank Dr Christina Strom-Moller for valuable references and comments on the manuscript. We thank the staff at EPIC and the participating general practitioners in the UK for their excellent cooperation. We also thank the Boston Collaborative Drug Surveillance Program (BCDSP) for providing access to the database.

Funding: this study was supported in part by a research grant from Pharmacia and Upjohn.

Conflicts of interest: none.

1 Mahoney MC, Burnett WS, Majerovics A, et al. The epidemiology of ophthalmic malignancies in New York State. Ophthalmology 1990;97:1143-7.

2 Singh J, Sioulis C, Cullen JF. Conjunctival melanoma. Arch Ophthalmol 1996;114:1528-9.

3 Jensen OA. Malignant melanoma of the iris. A 25-year analysis of Danish cases. Eur f Ophthalmol 1993;3:181-8.

4 Seregard S. Posterior uveal melanoma. The Swedish perspective. Acta Ophthalmol Scand 1996;74:315-29.

5 García Rodríguez LA, Pérez Gutthann S. Use of the UK General Practice Research Database for pharmacoepidemiology. Br f Clin Pharmacol 1998;45:419-25.

6 Jick H, Jick SS, Derby LE. Validation of information recorded on general practitioner based computerised data recorded on general practitioner based computerised dat
resource in the United Kingdom. BMF 1991;302:766-8

7 Ferlay J, Black RJ, Whelan SL, et al. Electronic database of Ferlay J, Black RJ, Whelan SL, et al. Electronic database of
cancer incidence in five continents. Vol VII. Lyon: International Agency for Research on Cancer, 1997: IARC CancerBase no 2 .

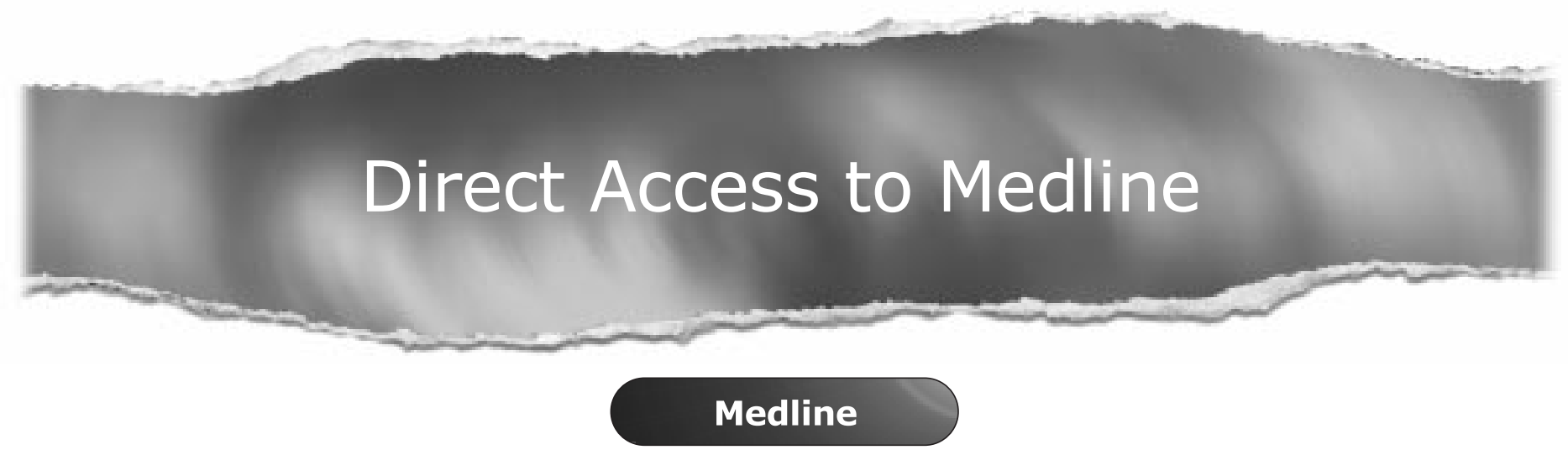

Link to Medline from the homepage and get straight into the National Library of Medicine's premier bibliographic database. Medline allows you to search across 9 million records of bibliographic citations and author abstracts from approximately 3,900 current biomedical journals.

www.jech.com 